\section{Carter to Speak at Annual Meeting}

Former president Jimmy Carter has agreed to speak at a special plenary session of the annual meeting on Thursday, August 31 at 5:15 p.m. at the Atlanta Hilton.

In addition, a special panel featuring the Carter Fellows and reception will be held at the Carter Library on Friday, September 1 .

\section{Wildavsky to Deliver Gaus Lecture}

Aaron Wildavsky has been selected to deliver the Gaus lecture at the 1989 annual meeting on Friday, September I at 5:30 p.m.

The selection committee, composed of Joseph LaPalombara, chair, Beryl Radin and James Carroll, said Wildavsky was their "enthusiastic and unanimous choice." The committee's charge was to select "a scholar who best embodies the joint tradition of political science and public administration and, more generally, to recognize achievement and encourage scholarship in public administration."

\section{Harold Lasswell Symposium Panel}

Program Chair Nelson W. Polsby has selected the panel "The End of Realignment: Atrophy of a Concept and Death of a Phenomenon" as the 1989 Harold Lasswell Symposium. The panel will be chaired by Harold Bass, Ouachita Baptist University, and will include papers by Byron E. Shafer, Nuffield College, Oxford University; Joel Sibley, Cornell University; and Everett Carll Ladd, University of Connecticut and Roper Center for Public Opinion Research. Walter Dean Burnham, University of Texas at Austin, and Samuel McSeveney, Vanderbilt University, will serve as discussants.

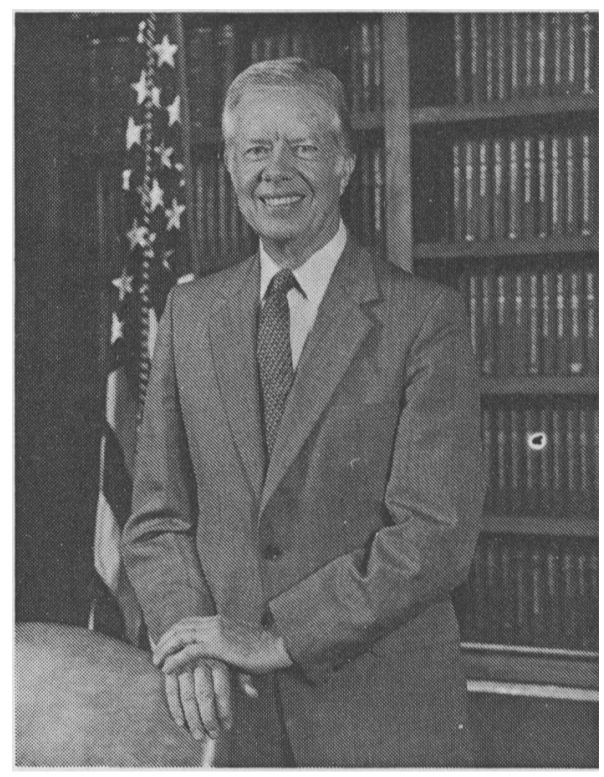

PRESIDENT JIMMY CARTER

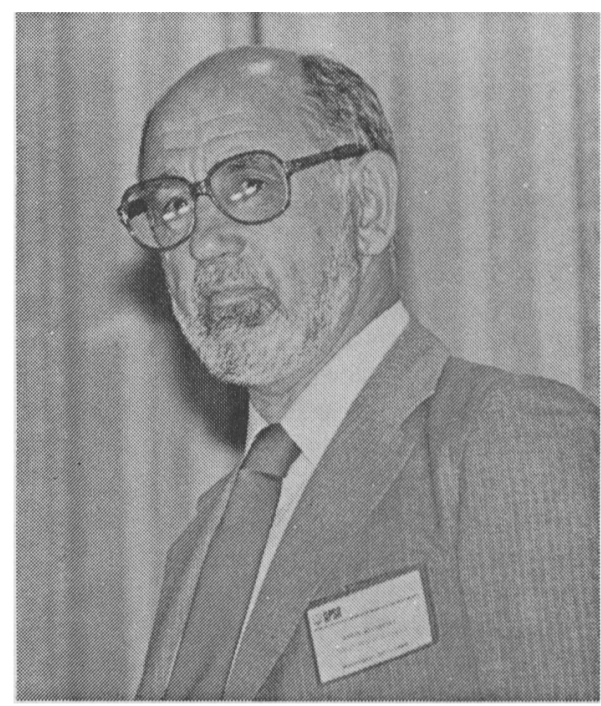

AARON WILDAVSKY 